\title{
Fertility variations in the recession context: the case of Greece
}

\author{
Alexandra Tragaki ${ }^{1 *}$ (D) and Christos Bagavos ${ }^{2}$
}

\author{
* Correspondence: atragaki@hua.gr \\ 'Department of Geography, \\ Harokopion University of Athens, 70, \\ El. Venizelou Ave, 17671 Athens, \\ Greece \\ Full list of author information is \\ available at the end of the article
}

\begin{abstract}
Research on the counter- or pro-cyclical nature of aggregate fertility over economic cycles has been inconclusive, as results vary significantly across regions and over time. This work examines the variations in Greek birth rates, and confirms that fertility rates in Greece have declined since 2010. Partly as a response to economic uncertainty, childbearing decisions have been revised downward, although not uniformly across population groups. According to our analysis, almost 40,000 fewer babies were born in Greece between 2010 and 2015 than would have been born if pre-recession fertility rates had remained unchanged. Those missing births are mainly attributed to women under age 30, as well as to non-employed women of all ages. In terms of birth order, most of the missing births are second- or higher-order births. Even if a catch-up process occurs in the years to come, the foregone births are already visible as a cavity on the population pyramid.
\end{abstract}

\section{Background}

High fertility rates have been traditionally associated with low levels of economic development. When living standards rise, the total number of children per woman declines, according to the demographic transition theory, which is based on evidence from around the world. After the demographic transition has been completed, both fertility and mortality are expected to remain at low levels. At this final stage of demographic transition, however, these assumptions about the relationship between economic cycles and fertility have been called into question (Andersson, 2000; Myrslylä, Kohler, \& Billari, 2009, 2011; Karaman Örsal \& Goldstein, 2010; Adserä, 2004). Few issues have intrigued demographers more than the relationship between economic performance and fertility in advanced economies. This relationship has been repeatedly tested over time and across regions and countries. The findings regarding the sign and the strength of this relationship have been somewhat contradictory. Although some scholars have suggested that fertility is counter-cyclical, the argument in favor of its pro-cyclical behavior has received stronger evidence-based support. It has, for example, been demonstrated that fertility tends to fall when the gross domestic product (GDP) declines or unemployment rises (Sobotka, Skirbekk, \& Philipov, 2011; Currie \& Schwandt, 2014). Other scholars have suggested that even if the economy-related variations appear to be important in period fertility, their imprint on cohort fertility rates may turn out to be limited or even nonexistent due to the postponement effect (Bongaarts \& Sobotka, 2012; Comoli, 2017). Thus, the question of whether fertility in more developed countries is pro- or counter-

(C) The Author(s). 2019 Open Access This article is distributed under the terms of the Creative Commons Attribution 4.0 International License (http://creativecommons.org/licenses/by/4.0/), which permits unrestricted use, distribution, and reproduction in any medium, provided you give appropriate credit to the original author(s) and the source, provide a link to the Creative Commons license, and indicate if changes were made. 
cyclical has yet to be resolved, and continues to stimulate a vibrant discussion among demographers (Harttgen \& Vollmer, 2014; Adserä, 2011).

The recent economic downturn, or "Great Recession," provides an additional case study for evaluating the quantum and the tempo effects that underlie changes in fertility. A number of studies on shifts in European fertility patterns under deteriorating economic conditions (Sobotka et al., 2011; Kreyenfeld et al., 2012; Balbo et al., 2013; Goldstein et al., 2013; Lanzieri, 2013) have observed a downward trend in birth rates. All of these studies have shown that there were shorter- or longer-term fertility adjustments in response to economic uncertainty. However, these findings have been mixed, as they have reported notable differences in fertility trends across countries, and among population sub-groups. There is, for example, evidence that a woman's age, educational level, employment and socio-economic status, and number of children are among the variables that influence her childbearing decisions (Bagavos \& Tragaki, 2017; Cazzola et al., 2016; Currie \& Schwandt, 2014). However, the results regarding the direction of the influence of these variables have been inconclusive. It appears that these findings were sensitive to the choice of country, to the time period examined, and to the length and the intensity of the economic downturn.

A number of scholars have observed that, for several reasons, the demographic effects of the recent financial crisis differed from those of previous economic downturns (i.e., Sobotka et al., 2011). First, compared to past periods, women today make up a much larger share of the labor force in general, and of the highly qualified workforce in particular. Second, as the relationship between fertility and female employment has turned positive, the effects on household prosperity of rising unemployment rates, salary reductions, and bleak employment prospects for women may have become more pronounced. Third, across most developed economies, fertility is already well below replacement level, and the mean age at first birth is already high. Thus, for a large share of women, the further postponement of childbearing would be equivalent to childlessness, and would therefore affect cohort indicators. The growing number of studies that are looking at how economic conditions are affecting fertility demonstrates the importance of this issue, and the magnitude of its multidimensional short- and longer-term consequences.

This paper examines fertility trends during the years of the Great Recession based on data from Greece. When investigating the recent economic crisis and its repercussions, the case of Greece may be considered unique for several different reasons. The main reason has to do with the country's level of exposure to the economic crisis: i.e., relative to the other EU countries, Greece experienced both the deepest and the longest economic recession. The second reason has to do with the country's fertility pattern: i.e., as very low and late fertility has long been the norm in Greece, the further postponement of childbearing would essentially eliminate the possibility of further procreation, and would thus affect not just period, but cohort total fertility rates (TFR). The main research question of this paper is whether significant age-, employment-, or parityrelated differences in women's reproductive reactions to the economic downturn could be observed in Greece. Our study period runs from 2000 to 2015, and is divided into two sub-periods: the pre-recession years (2000-2009) and the recession years (2010-2015). 


\section{Data and methods}

The aim of this study is to provide macro-level evidence on the interactions between economic downturns and fertility dynamics. Our analysis relies on aggregate economic data. Specifically, we use per capita GDP (expressed in PPP, USD) data provided by Eurostat to describe economic conditions; and annual data on male, female, and total unemployment rates by age, also provided by Eurostat, as a proxy for economic uncertainty. In addition, following the methodology suggested by Tragaki and Bagavos (2014), we merge period counts of births broken down by mother's age and employment status, which are published annually by the Hellenic Statistic Authority (EL.STAT.), with Labour Force Survey (LFS) data to compute age- and employment-specific fertility indicators. We calculate the main fertility indicators (namely, the crude birth rate and the total fertility rate), as well as group-specific fertility rates for 5 -year age groups (under $20,20-24, \ldots, 45-49$ ) by employment status (employed versus non-employed). The aforementioned indicators have been used to describe developments in group-specific fertility rates since 2000, and thus to evaluate the effects of the recession on these rates. It is important to stress that the "non-employed" group includes both unemployed and inactive women ${ }^{1}$. The fertility indicators could not be calculated for unemployed and inactive women separately because of inconsistencies in the definitions of unemployment used in our two sources; i.e., the vital statistics and the LFS.

In order to assess whether and, if so, to what extent the fertility decline was associated with the adverse economic conditions, we examined how the economic and the fertility indicators varied over time. Additionally, to measure the effects of changes in economic conditions on fertility decisions, and how these effects varied across age groups, we applied OLS regressions to year-over-year changes in the overall unemployment rate, and to annual changes in age-specific fertility rates, lagged by 1 year. All of the statistical analyses were performed using IBM-SPSS Statistics v23.

At a second level, we attempted to quantify changes in fertility behavior by estimating the number of births that would have occurred if the age-specific fertility rates had remained at the pre-recession levels (Johnson, 2014, 2016). To that end, recent birth data were combined with Eurostat annual estimates of the female population of childbearing ages. The number of "expected births" was estimated by applying pre-recessionary (the average of the years 2007-2009) age-specific fertility rates for women aged 15 to 49 to the actual female population age structure ${ }^{2}$. Thus, the age-specific fertility rates $f_{x}(2009)$ were applied to the population age structure of the years 2010 to 2015, as shown in the formula below.

$$
B(t)=\sum_{x=15}^{49} B_{x}(t)=\sum_{x=15}^{49} f_{x}(R) * P_{F, x}(t)
$$

where: $B(t)$ : the total number of births at year $t(t=2010,2011,2012,2013,2014$, 2015)

\footnotetext{
${ }^{1}$ For women aged 15-59, the share of unemployed women among the "non-employed" women varied from $21.1 \%$ in 2010 to $34.8 \%$ in 2015.

${ }^{2}$ The estimation of "missing births" could rely on alternative assumptions about the age-specific fertility rates used as the reference for the calculation of "expected births." Johnson $(2014,2016)$ estimated the number of missing births in the US while using as the reference the last year before the recession. Alternatively, it could be suggested that if the recession had not occurred, the 2004-2009 upward fertility trend could have continued uninterrupted for a couple of years. This study presents a rather modest scenario in which the reference age-specific fertility rates are given by the average of the last three years before the onset of the recession (2017-2019).
} 
$B_{x}(t)$ : the number of births to mothers of age $x$ at year $t$

$f_{x}(R)$ : reference fertility rate at age $\mathrm{x}$ (given by the average of the last 3 years prior to the recession, 2007-2009)

$P_{F, x}(t)$ : the female population of age $x$ at year $t$

The calculated number of "expected births" per year was then compared to the actual number of births reported by the EL.STAT. for each year of the 2010-2015 period. Estimating the difference between the expected and the actual number of births-i.e., the number of "missing births"-has been suggested as an alternative way of measuring changes in childbearing within the context of the latest economic downturn. Calculated at an annual level and broken down by the mother's age and employment status, and by birth order, missing births are used as a proxy for detecting differences in the specific attributes of the female population.

\section{Results}

\section{Fertility trends}

Starting in 1980, Greek fertility rates declined rapidly across all age groups. Within just a decade, the TFR had fallen from 2.22 to 1.42 . During the $1980 \mathrm{~s}$, the annual number of births decreased by more than 30\%; i.e., from more than 148,000 to slightly above 102,000. By the end of the twentieth century, overall fertility had stabilized at the alarmingly low level of 1.29 children per women, with a mere 100, 000 births registered annually (Fig. 1). As in most other European countries, the abrupt decline in fertility in Greece has been primarily driven by a trend among young adults toward postponing childbearing until later in life, after they have achieved their educational and professional goals (Kotzamanis et al., 2017). In

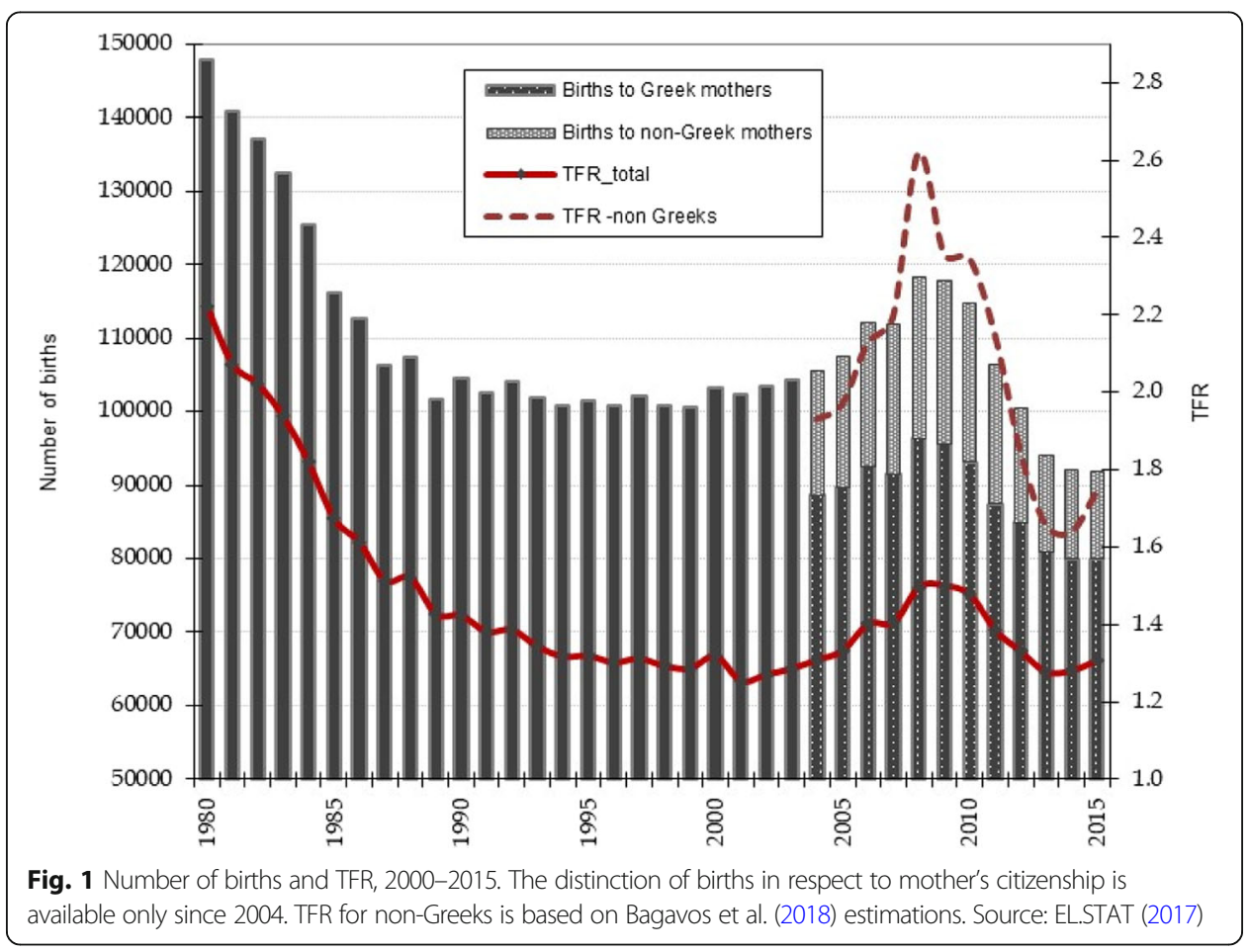


1980, there were 158 births per 1000 women aged 20 to 24, and 134 births per 1000 women aged 25 to 29; those numbers shrank to 87 and 97, respectively, in 1990; and then to 46 and 86, respectively, in 2000. In the 1980s and 1990s, birth rates among women in their twenties were significantly higher than those of women in their thirties. While this gap was narrowing over time, the mean age at motherhood increased by 1 year in the 1980s (from 25.5 in 1980 to 26.5 in 1990), and by two more years in the 1990s, before reaching 28.5 in 2000 (Kotzamanis \& Sofianopoulou, 2009).

At the turn of the millennium, a slight fertility recovery began that was driven by two forces: growing shares of births to immigrant mothers and increasing fertility rates among women in their thirties. Births to non-Greek mothers added around 20,000 newborn babies annually, pushing the number of births up to 119, 000 in 2008-the highest value recorded since 1985 (Bagavos et al., 2018). Fertility was also boosted by rising birth rates among women in their thirties due to the recuperation of previously postponed births (Kotzamanis et al. 2017). By 2005, for the first time in the country's history, the birth rates of women aged 30 to 34 exceeded those of women aged 25 to 29; 1 year later, the birth rates of women aged 35 to 39 exceeded those of women aged 20 to 24 (Fig. 2). The share of births to mothers aged 35 or older has been almost doubling every 10 years: in 2010, nearly one in four births was to a mother aged 35 or older, up from 15\% in 2000 and just $8 \%$ in 1990. Mostly as a result of delayed childbearing, the rising fertility rates of women aged 30 or older were not sufficient to raise the TFR any higher than 1.5. In the twenty-first century, women in Greece started following a "late and low" fertility pattern: i.e., late childbearing and low fertility. The slight recovery of fertility lasted less than 8 years, and ended when the economic crisis hit.

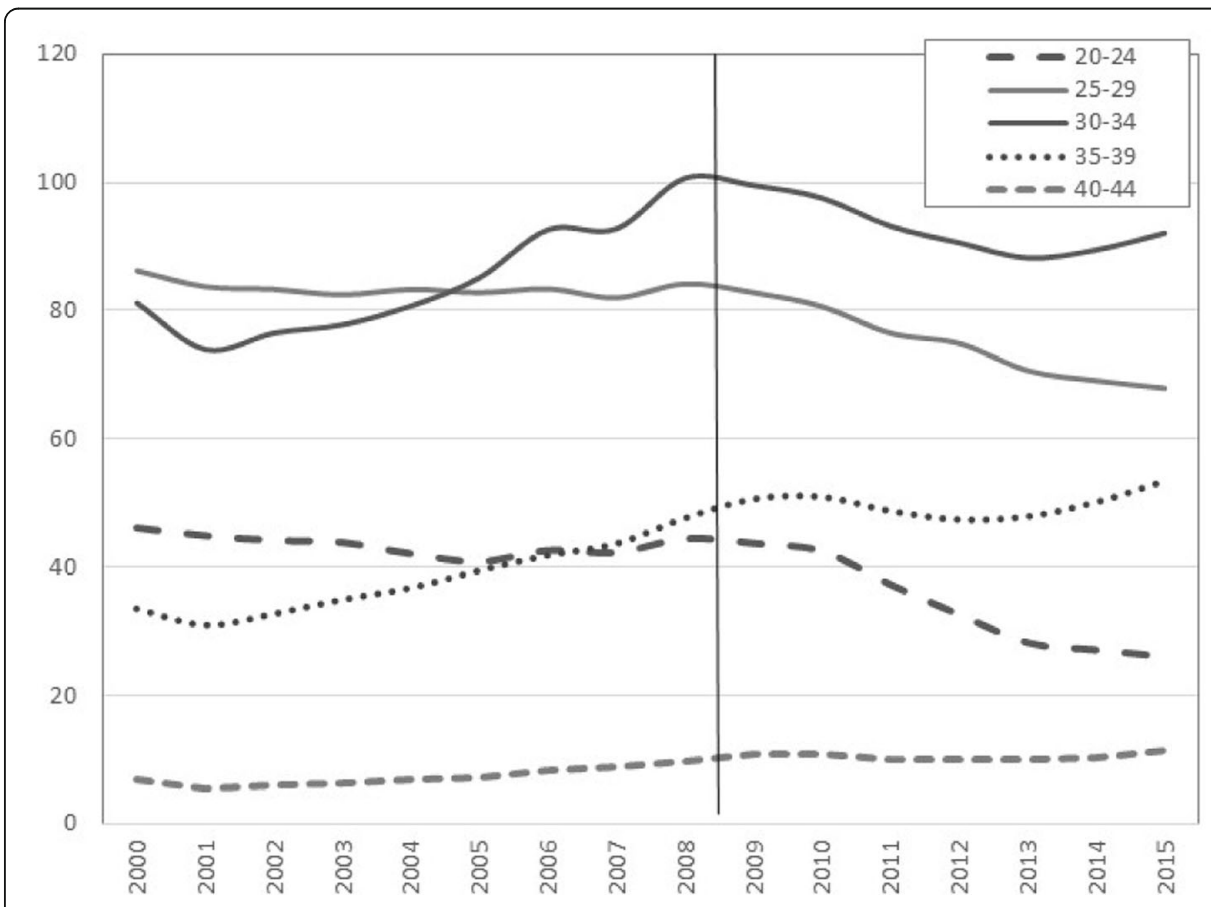

Fig. 2 Age-specific fertility rates (births per 1000 women), 2000-2015. Source: EL.STAT. (2017) and own calculations 
The association between fertility and economic uncertainty in Greece

Since 2009, Greece has endured not just one of the deepest, but the longest recession a developed country has ever experienced, at least since the end of World War II. According to official (revised) data, the economy first contracted in the final quarter of 2008, and then shrank for eight consecutive years (EL.STAT., 2018). Over the same period, the total number of unemployed individuals tripled, with youth unemployment and long-term unemployment rates reaching alarming levels. Growing uncertainty and bleak prospects created a pessimistic environment that had repercussions for all aspects of individual behavior, including childbearing. After the onset of the economic crisis, successive record-low numbers of births were registered annually. By 2015, birth numbers had reached their lowest level in six decades, the period TFR had fallen $13 \%$ to 1.28 , and age-specific fertility rates had decreased for all ages. Based on calculations not presented here, the mean age at childbirth appears to be the only fertility indicator for which the trend was not interrupted after 2009. Thus, the mean age continued rising to reach 31.3 in 2015-only half a year higher than the mean age at first birth.

It is, of course, difficult to assess the demographic impact of an unfolding crisis, as it is hard to disentangle the influence of adverse economic conditions from other concomitant behavioral or social developments. In this study, we use correlation analysis to examine the relationship between economic conditions and fertility, while acknowledging that this exercise offers only an indication of this association, and cannot establish any causality or provide sufficient evidence about their interaction. The graphical presentation of per capita GDP, expressed in purchasing power parity (PPP), and of TFR variations over the last 15 years supports the dominant perception that the economic recession and the fertility decline are linked. Figure 3 displays evidence of a "pro-cyclical relationship" between economic growth and fertility, but it also points to some interesting differences between the expansion and the recession years. Upward shifts in fertility as a response to

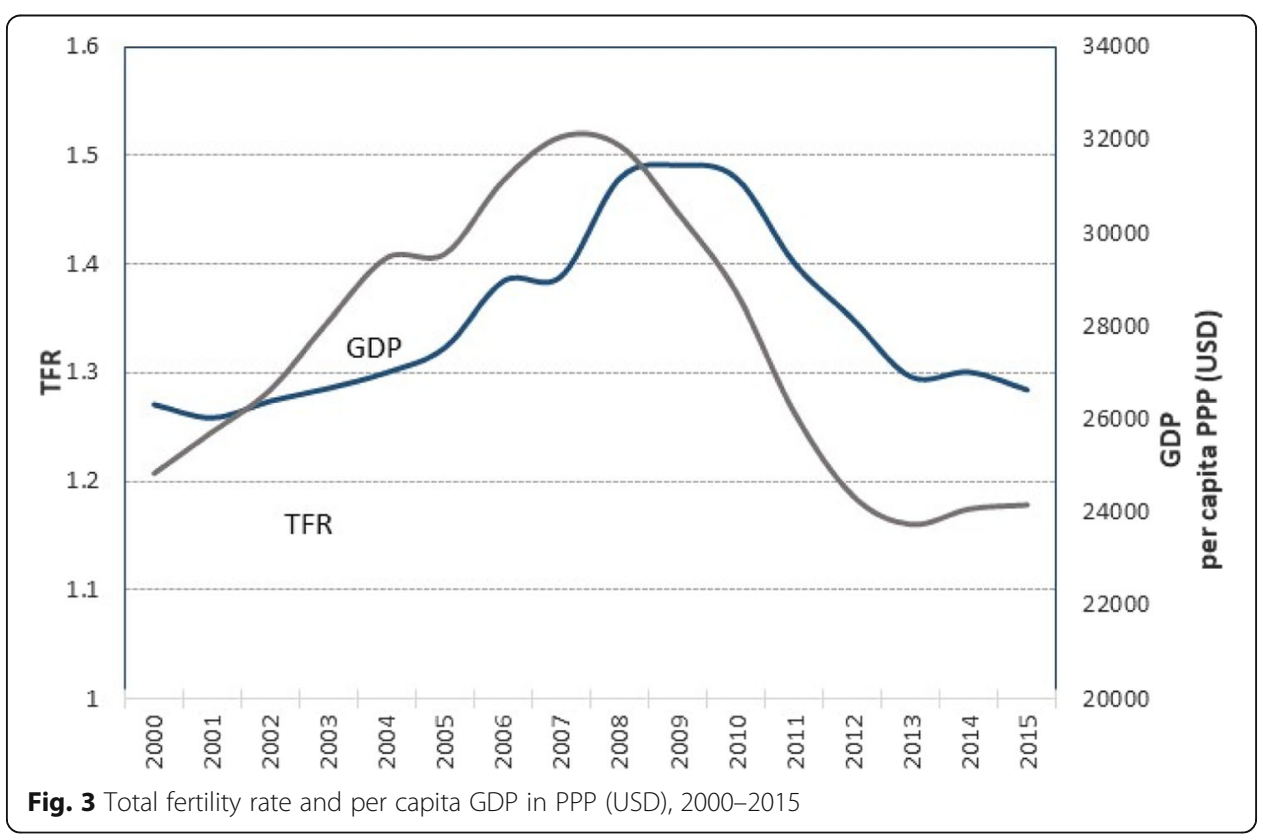


growth in the economy have become less pronounced, and are taking longer to materialize, than the downward fertility shifts during the years when economic conditions are deteriorating.

Figure 4a shows the annual birth rate and the male and female unemployment rates over the 2000-2015 period (the recession years are shaded). A negative relationship between unemployment and birth rates is clearly illustrated: after 2011, when the recession officially started, fertility (as reflected in the crude birth rate) plummeted, probably as a reaction to skyrocketing unemployment rates.

A scatterplot of year-over-year changes in the overall unemployment rates during the 1999-2014 period, and in the birth rates, lagged by 1 year, during the 20002015 period, verifies the negative association between those indicator variables (Fig. $4 \mathrm{~b})$. The straight line is produced by running a simple linear ordinary least squares (OLS) regression. The regression equation is found to be statistically significant $(F(1,14)=26.42, p<.000)$, with an adjusted $R^{2}$ of $62.8 \%$. The slope of the line is $-0.15(p<.001)$, which means that an increase in the unemployment rate of one percentage point is expected to produce a decrease of 0.15 percentage points in the number of births per 1000 persons.

Among all of the variables that condition fertility behavior, female age is the variable that is associated with the greatest constraints. Thus, it may be expected that reactions to adverse economic conditions are largely dictated by age. That assumption was confirmed when the previous analysis was repeated separately for six age groups $(15-19,20-24,25-29,30-34,35-39$, and 40-49) of the female population. The findings suggest that women tend to adjust their reproductive behavior in response to economic cycles differently at different ages. The younger a woman is, the more likely she is to postpone a birth during an economic downturn, and, thus, the stronger her negative response to increasing overall unemployment rates is likely to be. As Fig. 5 shows, for women in the age groups 15-19 $(\beta=0.30, p<$ $.05)$ and $20-24(\beta=0.25, p<.001)$, the negative effect is not only strongest, but is almost twice the size of the average effect across all age groups $(\beta=0.15, p<$ .001). As a woman's age increases, the relationship becomes weaker, and declines to almost zero after age 40. It should be stressed that among women in their thirties and forties, the negative relationship between changes in unemployment and fertility rates is not just very weak; it is no longer statistically significant. It could be argued that women over the age of 35 have more secure careers and feel less vulnerable to the risk of unemployment. Thus, our findings on potential connections between changing employment opportunities and childbearing decisions are inconclusive.

\section{Measuring the "missing births" of the 2010-2015 period}

The total number of births per year declined 20\% between 2010 and 2015, from 114,566 to 91,674 . Two factors are responsible for this decrease: shifts in fertility rates (or, differently stated, changes in fertility behavior) and a decrease in the female population of childbearing ages, mostly due to population aging.

In order to estimate the volume of births that failed to materialize due to falling fertility rates, we relied on formula (1), as presented in the "Data and methods" 


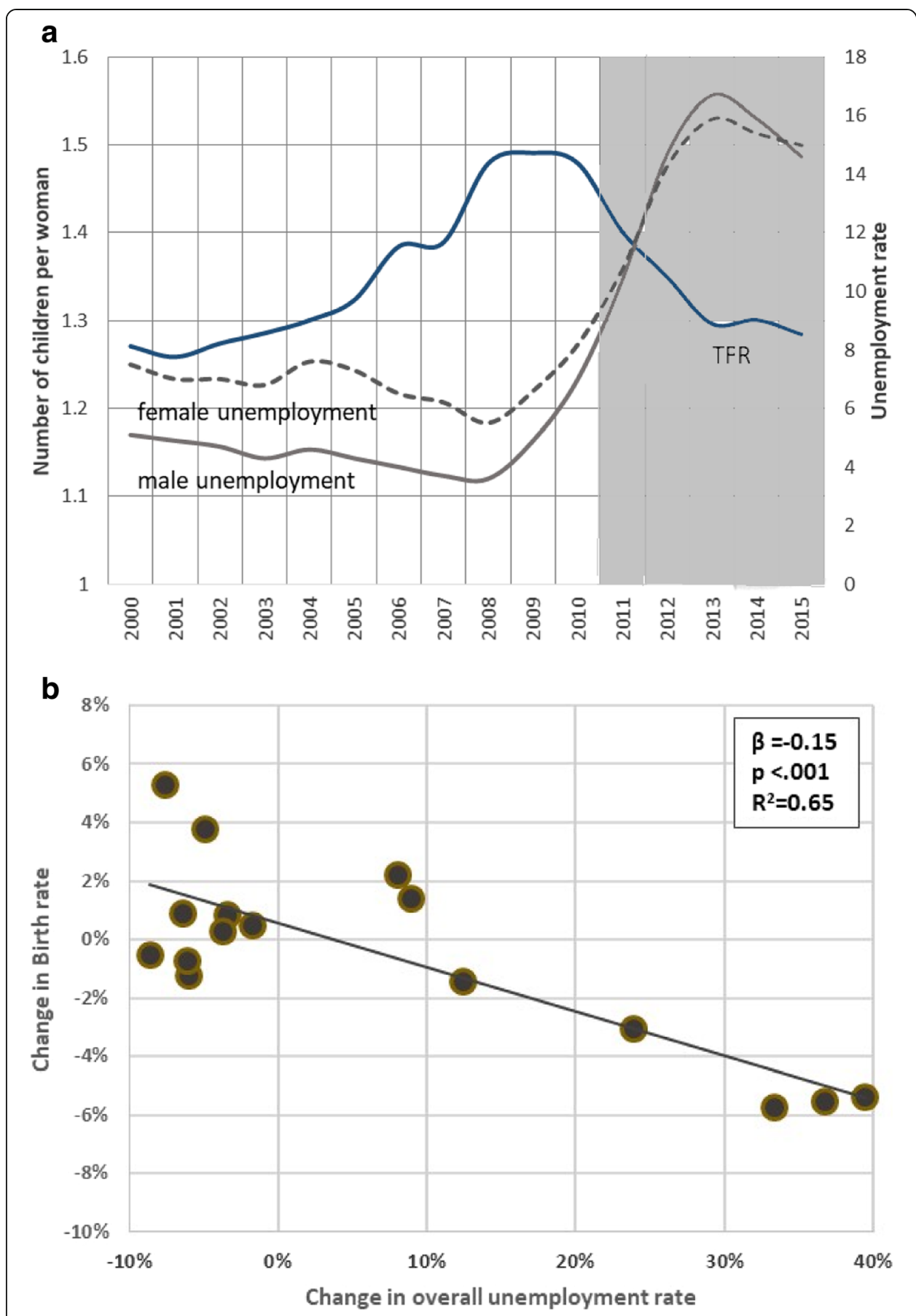

Fig. 4 a Total fertility rate versus male and female unemployment rates, 2000-2015. b Changes in crude birth rates versus unemployment rates, 2000-2015

section. Keeping the age-specific fertility rates frozen at their pre-recession levels (the average of the 2007-2009 period), the estimated annual number of births is called "expected births using pre-recession fertility rates," or simply "expected births." The difference between the expected and the actual number of births gives the annual number of "missing" births due to shifting fertility rates (Fig. 6). 


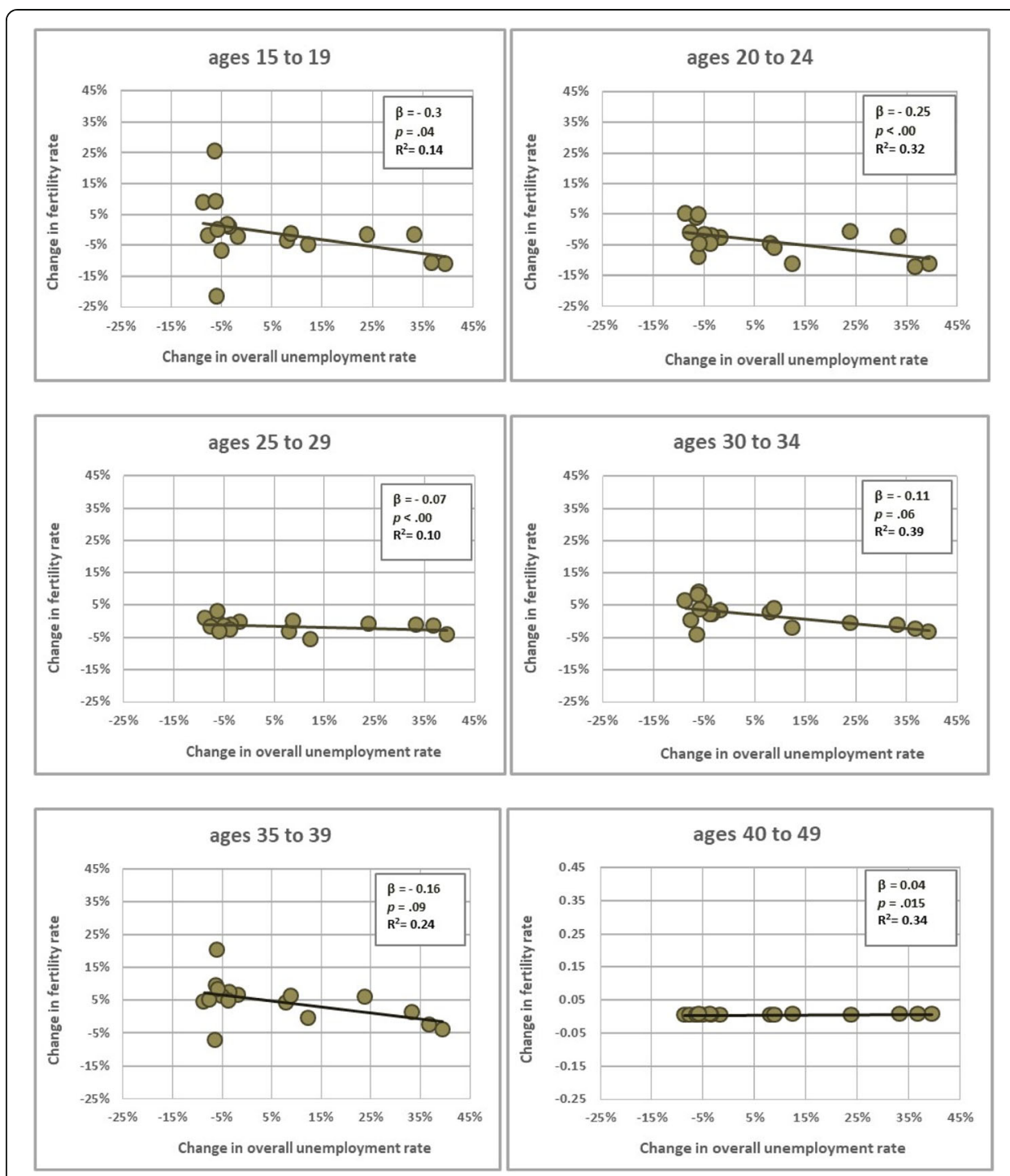

Fig. 5 Short-term relationship between changes in overall unemployment and age-specific birth rates

If the pre-recession age-specific fertility rates had been sustained through 2015,38 , 710 additional babies would have been born during the 2010-2015 period. Stated differently, there were about $7 \%$ fewer children aged $0-5$ in 2015 than there would have been if the pre-recession fertility rates had continued.

\section{Missing births by year}

The number of missing births started increasing rapidly immediately after the first year of the recession: the small surplus of about 1500 births that was registered in 2010 turned into a deficit of almost 50001 year later, and reached almost 11,000 births in 2013. After 2014, the annual number of missing births was no longer increasing, but remained persistently above 6000 (Fig. 7a). The deceleration observed during the last 2 years of the study period is explained by the declining numbers of missing births to mothers aged 35 or older. 


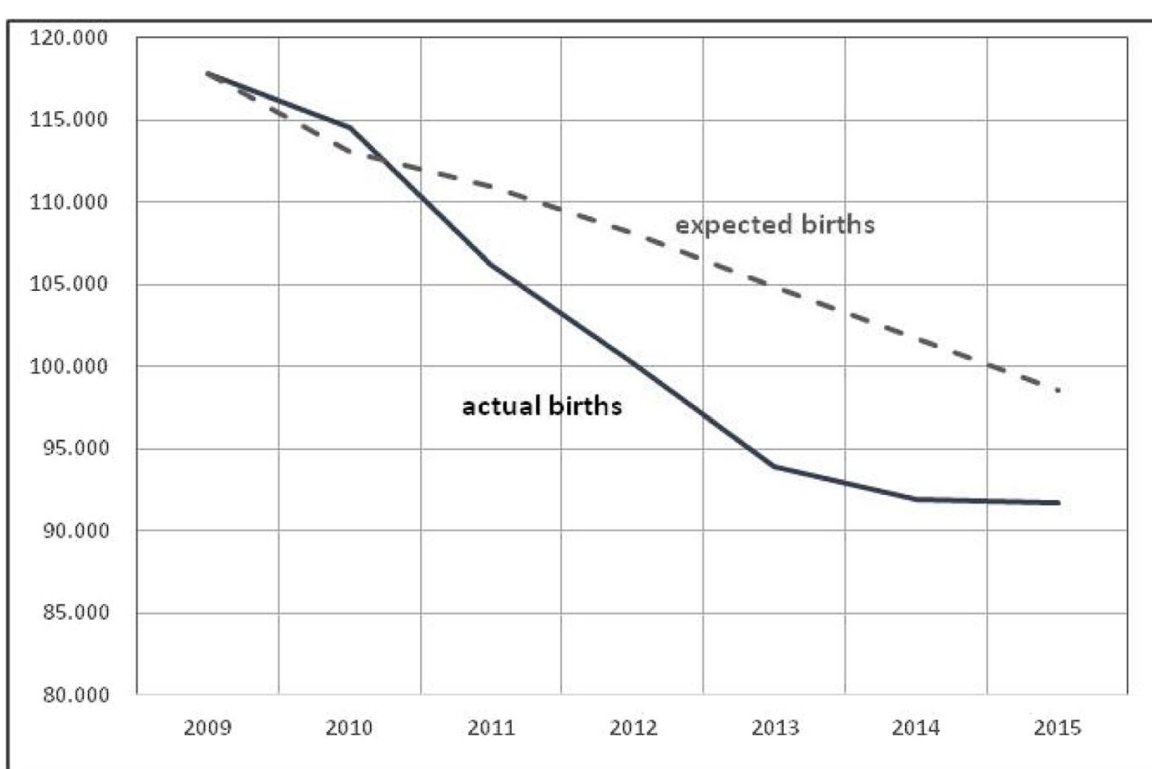

Note: Pre-recession rates are given by the three-year average (2007-2009) of age-specific fertility rates.

Fig. 6 Actual births compared to "expected" births using pre-recession fertility rates. Pre-recession rates are given by the 3-year average (2007-2009) of age-specific fertility rates

\section{Missing births by mother's age}

Over the 2010-2015 period, fertility was shifting to higher ages and the reproductive period was getting shorter, as indicated by two simultaneous and opposite trends: fertility rates were clearly declining among women under age 35, but they were steadily increasing among women of higher reproductive ages. The largest birth shortfalls were registered for women in their twenties and early thirties. By contrast, the actual numbers of births were significantly higher than the expected numbers of births for women between the ages of 35 and 49 (Fig. 7b). More than merely signaling the continuation of an already established trend, this fertility trend suggests that women were postponing childbearing during the years of economic hardship. A woman's age appears to be the most important determinant of how she adjusted her childbearing in response to the recession.

\section{Missing births by birth order}

A clear reduction in the number of births of all orders was registered during the 2010-2015 period. When the total number of missing births was broken down by birth order, some interesting findings emerged. First, there was a substantial redistribution of first births by the mother's age. In line with the postponement argument, the number of registered first births was lower than expected for mothers under age 28, but was higher than expected for those over age 30 (Fig. 8). The deficit in births among young mothers was completely counterbalanced by the excess births among older mothers. Thus, no missing first births were recorded as a result of changing age-specific fertility rates. Second, of the non-realized births, more than half $(54 \%)$ were second-order births, and almost four in ten (37\%) were third-order births (Fig. 7c). 


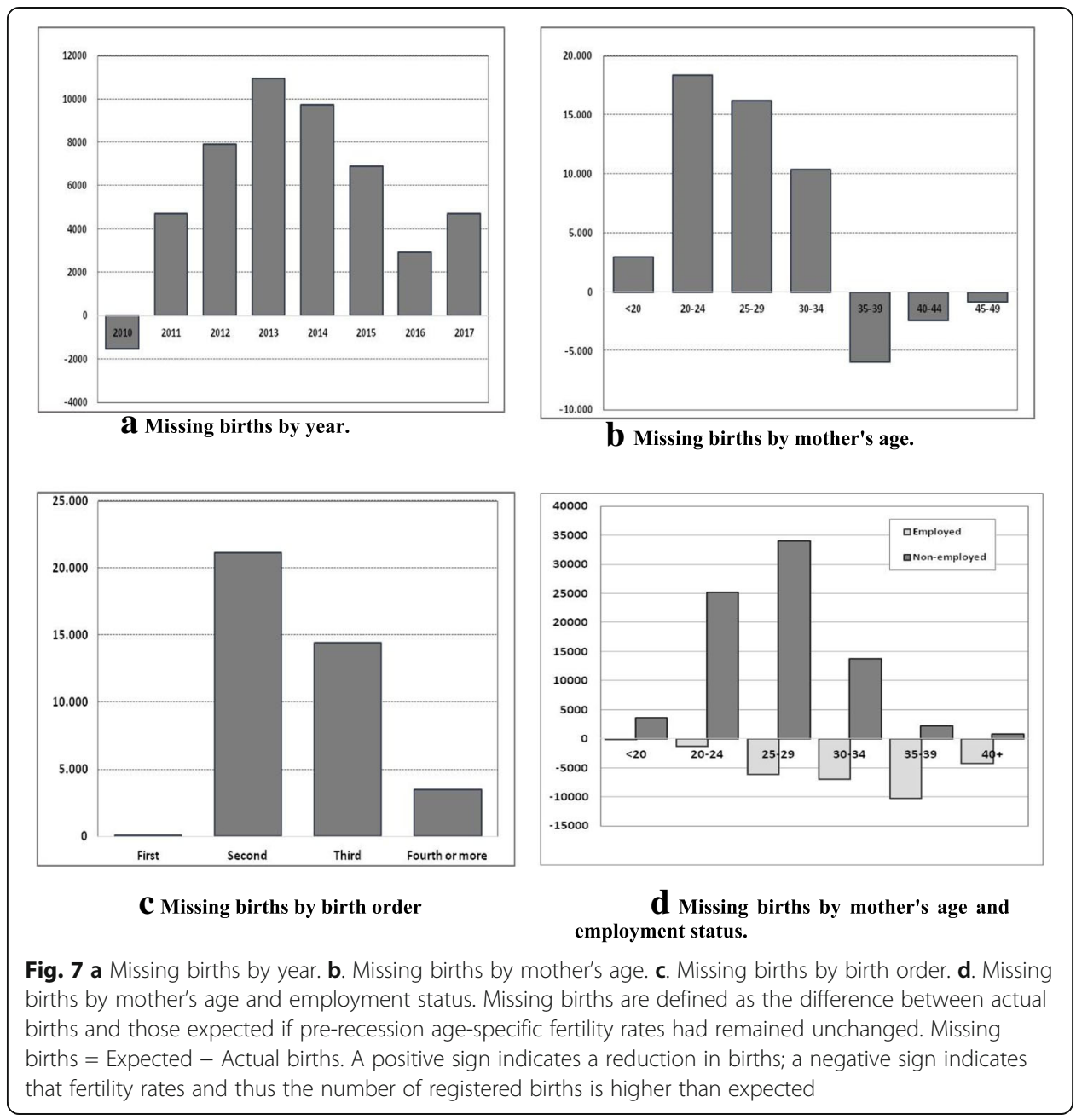

The evidence for the 6-year period examined here suggests that most of the first births we observed were delayed until later in a woman's life course (Fig. 8a), while large shares of second-, third-, and higher-births were foregone, at least for the duration of the recession (Fig. 8b-d). It is likely that births of order three or higher that have not been realized by mothers aged 35 or older will not be recovered in the years to come, which leaves a deficit of approximately 6000 children.

\section{Missing births by mother's employment status}

A marked employed-non-employed divide was observed across all ages. Overall, a surplus of births was found for all employed women regardless of their age. However, this excess was not high enough to offset the shortfall registered among non-employed women of all ages. The childbearing gap between employed and non-employed women was especially wide at ages 20-29, when the loss of births is important (Fig. 7d). The deficit of births became smaller for women in their early thirties, and turned into a surplus after the age of 35 . This finding links declining births to economic uncertainty, and underlines the point that employment status was a major force behind the birth postponement observed among young women. 


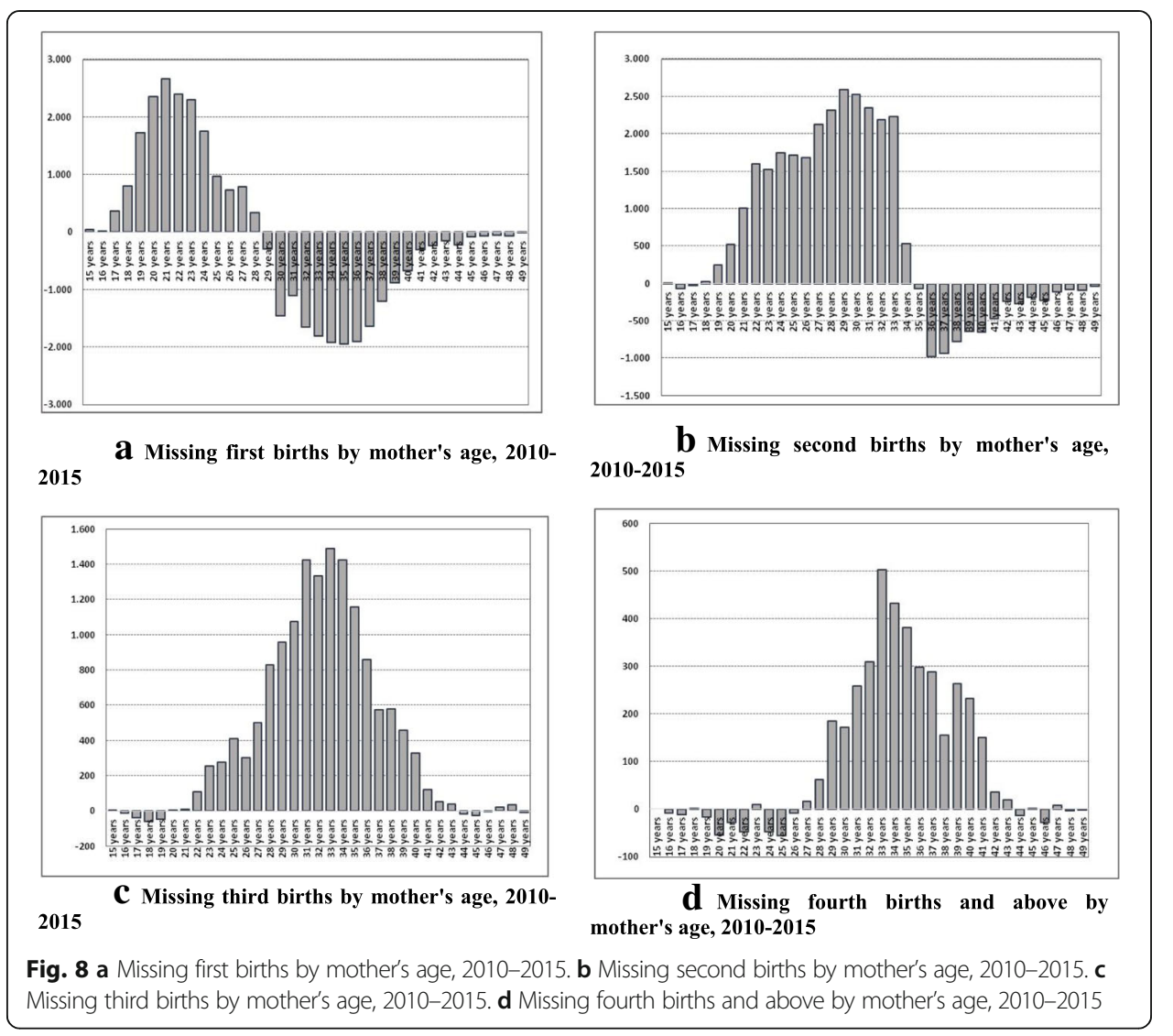

The postponement effect seems to have diminished as women grew older. When women were approaching the biological limits of fecundity (strictly defined by age), all other constraints became less significant if a desired birth had not yet been realized. Moreover, the longer the bad economic conditions lasted, the larger the number of "postponers" who were at risk of reaching the age at which childbearing is no longer possible. This may explain why the impact of the recession (measured by the volume of missing births attributed to changing fertility rates) did not increase further after 2014. However, this finding certainly does not signal that a recovery or even a stabilization of fertility had occurred.

\section{Discussion}

The reactions of fertility trends to socioeconomic changes are usually detected through variations in the (age-specific) fertility rates. This study has offered an alternative approach to investigating this relationship by focusing not on the changing indicators, but on the volume of births that did not occur due to shifting fertility rates. A shortfall of births may have resulted from a decrease in the number of women of childbearing ages, or from changes in fertility behavior, or both. The aim of this paper was to disentangle the aging effect from the behavioral effect by focusing on declines in birth numbers due to reduced fertility rates. To do so, we estimated the number of births that would have occurred if pre-recession fertility rates had remained unchanged. Moreover, we explored how missing births varied by the mother's age and employment status, as well as by birth order. 
Our results indicate that women who belonged to different age groups had different childbearing experiences and prospects, and thus tended to have different reactions to changing economic and social conditions. This was also found to be the case after the employment status was taken into account. Our findings suggest that there was a birth deficit due to childbearing adjustments among women under age 30, among nonemployed women of all ages, and among women who already had one child. Interestingly, we found that despite the bad economic conditions, there was a surplus of births to mothers who were over age 30 or were employed. Thus, three divides in fertility behavior following the onset of the recession emerged: i.e., between younger (below age 30) and older (above age 30) women; between employed and non-employed women; and between women who were childless and who had one or more children. The first divide is likely attributable to "postponers" approaching the biological limits for having children, especially if they were still childless. Our findings suggest that there was a strong trend toward delaying the first birth until after age 30, or even age 35 . The second divide reinforces the argument that birth numbers can decline in response to poor economic conditions. Female employment was found to be a factor that rendered women's childbearing decisions more resilient to the general economic conditions. Among employed women of all ages, fertility rates were unchanged or even slightly higher during the recession years. As male-dominated jobs have been the hardest hit by the recession, the share of women who out-earn their husbands has been gradually increasing. Thus, fertility decisions are more likely to hinge on a woman's earnings and career prospects than was the case in previous decades. This is a finding that should be of interest to policy-makers, and that merits further investigation.

Moreover, during the 2010-2015 period, no loss in first births was registered. The missing births we detected were for orders higher than one. According to our estimations, there were more than 21,000 and 14,400 missing births of the second and the third order, respectively. Stated differently, one out of ten second births and one out of four third births were foregone during the aforementioned period. Although it is still too early to fully assess the implications of these developments for cohort fertility rates, the number of families with two or more children seems to be shrinking, while the impact of missing births is already becoming apparent at the bottom of the Greek population pyramid.

As the aim of our approach was to examine childbearing decisions within an unfavorable economic context, we regret that, due to inconsistencies in the definitions used in different sources, we were unable to analyze unemployed women as a separate group. Moreover, if the estimated female population data by educational level had been more detailed (1-year age groups), we would have been able to allocate the missing births by the mother's education level. Despite these limitations, this study offers an alternative perspective on the implications of economic conditions for childbearing decisions, based on the estimation of the "number of missing births due to fertility changes," and using as a reference the average of the 2007-2009 fertility rates by age. We argued that this deficit is partly related to the ongoing economic crisis. The allocation of missing births by specific attributes (mother's age and employment status, and birth order) provides insights into the drivers of falling births. Thus, our findings can be seen contributing to the ongoing debate about the effects of economic conditions on childbearing, and may provide some ideas for actions that could be taken to lessen the 
negative impact of downturns. It should, however, be mentioned that, due to the decline in the size of the female population of prime childbearing ages, the total annual number of births in Greece would have declined even if the recession had not occurred. Between 2009 and 2015, the number of women between the ages of 25 and 35 decreased by 125,000 , or $14 \%$. This crucial development is partly the result of the downward trend in birth rates since the early 1980s. There is, however, increasing evidence that during the recession, the number of young and middle-aged adults who fled the country was high enough to have further deformed the population pyramid at childbearing ages. This is an additional implication of the crisis for demographic dynamics in Greece that has not been discussed in this work. We intend to examine this issue separately in future research, in order to give it the attention it deserves.

Finally, we should point out that a deficit in births after 2010 meant that there were fewer children aged 0-5 in 2015. At the moment, there is no sign that these births will be recovered in the years to come; and, even if they are, a cavity is already built into the population pyramid.

Acknowledgements

Not applicable.

\section{Authors' contribution}

Authors have equally contributed to this work. Both authors read and approved the final manuscript.

Funding

Not applicable.

\section{Availability of data and materials}

Data used in this paper are publicly available by the EUROSTAT database at http://ec.europa.eu/eurostat/data/ database.

\section{Competing interests}

The authors declare that they have no competing interests.

\section{Author details}

${ }^{1}$ Department of Geography, Harokopion University of Athens, 70, El. Venizelou Ave, 17671 Athens, Greece. ${ }^{2}$ Panteion University, Athens, Greece.

Received: 13 March 2018 Accepted: 12 August 2019

Published online: 03 September 2019

\section{References}

Adserä, A. (2004). Changing fertility rates in developed countries. The impact of labor market institutions. Journal of Population Economics, 17: 17-43.

Adserä, A. (2011). Where are the babies? Labor market conditions and fertility in Europe. European Journal of Population, 27(1), $1-32$.

Andersson, G. (2000). The impact of labour-force participation on childbearing behaviour: Pro-cyclical fertility in Sweden during the 1980s and the 1990s. European Journal of Population, 16(4), 293-333.

Bagavos, C. and A. Tragaki (2017) The compositional effects of education and employment on Greek male and female fertility rates during 2000-2014 Demographic Research, Vol.36, Article 47, pp:1435-1452.

Bagavos, C., Verropoulou, G., \& Tsimbos, C. (2018). Assessing the contribution of foreign women to period fertility in Greece, 2004-2012. Population (English Edition), 73, 115-129.

Balbo, N., Billari, F. C., \& Mills, M. (2013). Fertility in advanced societies: A review of research. European Journal of Population, 29(1), 1-38.

Bongaarts, J and T. Sobotka (2012) A demographic explanation for the recent rise in European fertility. Pop Dev. Rev. 38(1): $83-120$.

Cazzola, A., Pasquini, L., \& Angeli, A. (2016). The relationship between unemployment and fertility in Italy: A time-series analysis. Demographic Research, 34(1), 1-38.

Comolli, C. L. (2017). The fertility response to the Great Recession in Europe and the United States: Structural economic conditions and perceived economic uncertainty Demographic research. Article, 36(51), 1549-1600.

Currie, J., \& Schwandt, H. (2014). Short- and long-term effects of unemployment on fertility. PNAS, 111(41), 14734-14739.

EL.STAT. (2017) Annual data on births in Greece by mother's age, education level and employment status, 1980-2015. Available at

EL.STAT. (2018) The Greek economy. Available at http://www.statistics.gr/documents/20181/7146171/greek_economy_16 02_2018.pdf/4de404ac-9b88-4b01-916c-f7e0a67dd597?platform=hootsuite. Accessed 28 February 2018 
Goldstein, J. R., Kreyenfeld, M., Jasilioniene, A., \& Karaman Örsal, D. D. (2013). Fertility reactions to the 'Great Recession' in Europe: Recent evidence from order-specific data. Demographic Research, 29(4), 85-104.

Harttgen, K. and Vollmer, S. (2014) A Reversal in the Relationship of Human Development with Fertility?. Demography 51(1): 173-184. https://doi.org/10.1007/s13524-013-0252-y.

Johnson, K. (2014). The hidden cost of the recession. Carsey Research, National Fact Sheet \#26, Winter 2014 University of New Hampshire, available at: https://scholars.unh.edu/cgi/viewcontent.cgi?referer=https://www.google.gr/\&httpsredir= 1\&article=1230\&context=carsey. Accessed 8 Feb 2018.

Johnson, K. (2016). U.S. Births remain low as the great recession wanes. Carsey Research, National Fact Sheet \#34, Summer 2016. University of New Hampshire. available at https://scholars.unh.edu/cgi/viewcontent.cgi?referer=https://www.google. gr/\&httpsredir=1\&article=1274\&context=carsey. Accessed 8 Feb 2018.

Karaman Örsal, D.D. \& Goldstein, J. (2010). The increasing importance of economic conditions on fertility, MPIDR Working Paper 2010-014 Rostock: Max Planck Institute for Demographic Research. http://www.demogr.mpg.de/papers/working/ wp-2010-014.pdf. Accessed 13 Mar 2014.

Kotzamanis, B., Baltas, P., \& Kostaki, A. (2017). The trend of period fertility in Greece and its changes during the current economic recession. Population Review, 56(2), 30-48.

Kotzamanis B. and K. Sofianopoulou (2009) "Fertility and Reproduction in Greece since WWII" EKE 124A', pp. 3-38. (in Greek). Kreyenfeld, M., Andersson, G., \& Pailhé, A. (2012). (Eds.). Economic uncertainty and family dynamics. Demographic Research, Special Collection, 12.

Lanzieri, G. (2013). Towards a 'baby recession' in Europe? Differential fertility trends during the economic crisis. Eurostat Statistics in Focus 13/2013. http://epp.eurostat.ec.europa.eu/cache/ITY_OFFPUB/KS-SF-13-013/EN/KS-SF-13-013-EN.PDF. Accessed 2 May 2014.

Myrskylä, M., Kohler, H.-P., \& Billari, F. (2009). Advances in development reverse fertility declines. Nature, 460, 741-743.

Myrskylä, M., H-P Kohler and F. Billari (2011) High development and fertility: Fertility at older reproductive ages and gender equality explain the positive link MPIDR Working Paper WP 2001-017.

Sobotka, T., Skirbekk, V., \& Philipov, D. (2011). Economic recession and fertility in the developed world. Population and Development Review, 37(2), 267-306.

Tragaki, A., \& Bagavos, C. (2014). Male fertility in Greece: trends and differentials by education level and employment status. Demographic Research, 31(6), 137-160.

\section{Publisher's Note}

Springer Nature remains neutral with regard to jurisdictional claims in published maps and institutional affiliations.

\section{Submit your manuscript to a SpringerOpen ${ }^{\circ}$ journal and benefit from:}

- Convenient online submission

- Rigorous peer review

- Open access: articles freely available online

- High visibility within the field

- Retaining the copyright to your article

Submit your next manuscript at $\boldsymbol{\nabla}$ springeropen.com 